\title{
Public reactions towards wind energy instalments. Case study: Romania and the Netherlands
}

\author{
Maria Alexandra NICHIFOR \\ The Bucharest University of Economic Studies, Bucharest, Romania \\ maria.nichifor@fabiz.ase.ro
}

\begin{abstract}
Wind energy experienced an exponential development in the past two decades, forming a main source of energy today, but also a frequently encountered issue of debate due to the increased proximity of wind turbines to citizens' residence, especially in the case of the Western part of the European Union. Although the benefits of renewable sources of energy represent a compulsory effort towards ensuring sustainable energy strategies for the future, due to the increased pressure of balancing climate change, limitation of traditional energy resources and economic competition, the expansion of wind parks has caused strong reactions of local communities in many regions leading to the reorganization of public exposure strategies of many companies in the field. This research intends to offer a sample of public perceptions of wind turbines depending on several influence factors, based on the answers of 64 Dutch citizens and 40 Romanian respondents. Through the implementation of the Delphi method based on questionnaires and interviews, an overview of perceptions towards placement of wind turbines in the two analyzed countries has been offered, providing significant answers to the influence factors of public reactions for or against wind turbines. The main results of the research revealed the importance of financial benefits in increasing public acceptance of wind farms, as well as several subjective factors, such as the visual impact of wind turbines and onshore or offshore placement, that contribute to a positive or negative behavior of citizens towards it.
\end{abstract}

Keywords: wind energy, perceptions, public acceptance, offshore wind energy.

Please cite the article as follows: Nichifor, M.A. (2016), "Public reactions towards wind energy instalments. Case study: Romania and the Netherlands", Management \& Marketing. Challenges for the Knowledge Society, Vol. 11, No. 3, pp. 532-543. DOI: 10.1515/mmcks-2016-0014

\section{Introduction}

Wind power has encountered a significant development in the past years cumulating a level of 141758,8 MW installed capacities in the European Union in 2015 (EWEA, 2015). Within the European Union Romania is comparable in terms of installed wind energy capacities $2975,9 \mathrm{MW}$ at the end of 2015 with the Netherlands $3431 \mathrm{MW}$ and Ireland 2486,3 MW (EWEA, 2015). In this context, Romania has evolved exponentially as installed and potential capacity of wind energy due to its broad available surface, subvention scheme and investments of wind energy producers that focused their efforts to this region. Similarly, the wind energy sector in the Netherlands has evolved towards the 2020 objective of $16 \%$ target of renewable energy (Eggink, 2013), but is facing numerous protests in the last years due to a more restrained available surface and already present negative effects of wind turbines.

Although wind energy causes no damaging effects in terms of pollution, greenhouse gas emissions, being one of the cleanest sources of renewable energy, the expansion of wind turbines closer or within residential areas in many regions has 
become an issue due to the opposition of citizens living in the neighbourhood claiming the negative effects of this renewable energy technology. Several authors have investigated this phenomenon, as well as its causes originating in more factors, such as the project phase, distance from the residential area, wind turbines design, mentality of the citizens and other reasons. For example, Abe et al. (2016) mention in their study destruction of landscape, noise, bird fatalities, accidents, low frequency vibration as some of the main reasons for opposition towards wind turbines. The authors also emphasize the risk of wind turbines accidents because of natural causes or inadequate maintenance that can be destructive also to the residential area where they are placed. On the contrary, other studies demonstrate still there is a focus on the development of wind turbines, for example the Eurobarometer in 2011 study indicates $89 \%$ of EU inhabitants have a positive attitude towards wind energy, that can provide numerous advantages such as jobs, contributing to economic wealth and minimizing the climate change effect (EWEA, 2016). Another issue is that of placing offshore wind turbines that seem secured from opposition of stakeholders, but have also encountered protests from public opinion. The study of Lilley et al. (2010) shows that offshore wind turbines should be placed at least $16 \mathrm{~km}$ apart from the shore, as they indeed do decrease slightly the tourism in the region if they are visible. While generally, it is considered, that the offshore wind projects are not exposed to the public protests risk and sometimes are contributing to the increased public acceptance more authors have revealed the opposite: in the cases of Jay (2008) and Wolsink (2010) their research indicated offshore wind turbines affect the routes of certain fish species, thus, sea life, have been the subject of tourism agencies protests and public protests, as they are also approaching shores in the case of some regions. These risks of wind turbines, although not reported with a high incidence, have led to the necessity of wind energy producers to adopt strategies of cooperation development with citizens, NGOs, local government institutions and other key stakeholders in order to prevent protests after the construction phase and ensure already before the consent of the parties. Thus, the necessity of involving other affected parties by the instalment of wind projects is increasing with the expansion of wind parks across the globe.

The present paper intends to offer an overview of public perceptions on wind turbines placement depending on subjective factors, such as the design, landscape impact, etc. and objective factors, such as potential property value decrease of regions close to the wind project, but also the interest of the selected participants in supporting renewable energy. Furthermore, potential methods of convincing citizens to accept a potential wind project in their residential area have been a subject of interest for the investigation.

The study was based on two hypotheses:

H1: The majority of the Dutch and Romanian respondents will consider the visual impact through light colors of a wind turbine as having a high impact on increasing public acceptance.

H2: The majority of the Dutch citizens would accept to pay $25 \%$ more for renewable energy for their own consumption in order to support this sector financially, while the majority of the Romanian respondents would not be willing to pay anything additionally. This hypothesis was based on financial causes. 


\section{Literature review}

Wind parks are occupying more significant surfaces globally, therefore becoming often a daily element of the human habitat, especially in the case of wind turbines placed in residential areas. The expansion of wind farms has led to different reactions of citizens regarding the wind turbines, several of them developing the NIMBY-effect (not in my back yard phenomena). This already expanded phenomenon, NIMBY, has led to the development of research in the field in order to gain more acceptance from the citizens.

However, authors like Groothuis et al. (2008) explained that people with an orientation towards renewable energy, that believe wind energy should be used as a clean source of energy, tend to have a more positive feeling towards wind parks. Thus, more authors link the behavior of citizens towards wind parks to different factors, from the mentality towards the necessity and advantages of wind energy over the years to the financial benefits gained from wind energy projects (Navrud and Brăten (2007), Groothuis et al. (2008)). The authors revealed that financial compensation forms tend to increase the acceptance of wind turbines over time. Other authors observed a more negative attitude towards wind turbines in the planning, announcement phase of constructing a wind park in comparison to the following phases, where the hostility towards wind parks decreases (Wolsink 2007). Wolsink (2007) explains it is because people do not want to bear personal costs through this development of wind turbines construction although they are familiar with the benefits on the long term of such a project. In another study, Wolsink (2010) relates the negative reactions against wind turbines instalment to disturbance caused by them, such as visual impact on the landscape, shadow flickering, electromagnetic interference, casualties among birds, bats and other fauna species, possible health issues of humans, like hearing loss, visual epilepsy, affecting marine sea life, etc.

As methods of increasing public acceptance of wind turbines construction companies have developed several methods besides financial gains, such as in the case of Eneco and Vattenfall in the Netherlands, that adopted the following procedure in the planning phase: "organising information evenings for the local community, publishing plans and maintaining a fixed period for the community to provide their interest and opinion" or to object, as well as working with the government for establishing suggestions for wind turbines placement, thus practically involving the public in the planning of the wind park through early involvement (Eggink, 2013). This early involvement of key stakeholders is considered by the author as crucial for gaining efficiently and on time acceptance of stakeholders at least in the case of the Netherlands, otherwise facing the risk of delay, which can lead to costs, legal issues and even project risk.

In the Netherlands the protests against wind turbines have intensified in the last ten years due to the increased proximity of wind turbines to citizens habitats and to their frequency on surface unit, which led to disturbance of residential areas and negative reactions, such as in 2015 when Dutch citizens complained to the European Commission against Belgian wind turbines close to the Dutch-Belgian border only $250 \mathrm{~m}$ from their residence (Blyth, 2015). Offshore wind parks may seem more protected of the public opposition due to the fact they do not affect onshore habitats and thus are less visible and disturbing to citizens, however in the case of the 
Netherlands they are not, as proven by several protests of tourism agencies and citizens (DutchNews, 2014). Although the Netherlands is currently struggling towards reaching the 16\% target of renewable energy until 2020 (Eggink, 2013), a main issue is represented by the construction of wind turbines and renewable energy instalments and avoiding negative citizens reactions, which has proven to be a higher challenge than expected. Public negative reactions can have damaging effects not only on the government image, but also on the companies' revenue and costs, projects delaying or cancelling even if complaints of the public may be subjective (David Suzuki Foundation, 2013).

Regarding the diminishing of negative effects of wind turbines to flora, fauna and the environment, Berndt (2015) explained, specific materials must be used to place wind turbines on, in order to diminish CO2 emissions, such as the "use of 32 $\mathrm{MPa}$ class concrete (rather than $40 \mathrm{MPa}$ ), that can reduce the concrete generated emissions by at least 11\%". Regarding the public, their reaction will depend on the assessment of costs, potential risks and benefits of a wind energy project and because frequently the public does not have a complex knowledge of the impact and benefits of such a project, the assessment is generally subjective and depending on the exposure and involvement and even co-ownership of the project the company offers to them in the planning phase, the distance and visual elements of the wind turbines, as well as the subjective mentality factors of the individuals assessing (De Boer and Zaima, 2013).

Thus, the involvement of the public, local communities and local governments and their direct benefits from wind energy projects seem to play an essential role in the increased acceptance of wind turbines placement, as well as the efforts of informing population on a mass scale about the necessity of such projects in meeting the renewable energy targets and in balancing the need for sustainability with the need of increased energy consumption, that will only be durable through clean sources of energy.

\section{Methodology}

By using the Delphi method with interviews and questionnaires for a broader practical approach, the study was made by involving 64 Dutch citizens and 40 Romanian respondents, who were willing to participate in the inquiry in order to investigate potential similar or opposite public perceptions of wind turbines in the case of the two analyzed countries, that differ as citizens mentality, surface and wind parks development.

In order to distinguish between perceptions of citizens owning their property in a certain residence and the ones that rent or still live with their parents, the first classification was based on this factor: of the Romanian respondents $96 \%$ were owners of their own apartment, while only $6 \%$ were renting or were still living with parents, the latter only in the case of students.

This classification was chosen based on the hypothesis that citizens owning their own property would have a stronger sense of 'protecting' or being more cautious when a new element would appear in their environment, such as a wind turbine than the ones who were not renting and thus did not have the "owner feeling" over their own property. The vast majority of Dutch participants, respectively $66 \%$ of the Dutch 
respondents did not own their own apartment, thus renting or living with the family or roommate. The occupation of the interviewed participants ranged from the research field to medicine, banking and financing, journalism, consultancy, translations and other fields. Most of the participating citizens had not been exposed directly to the wind energy field. 58\% of the Romanian and Dutch respondents were below 35 years old.

The inquiry occurred in two parts: the first part of the questionnaires offered in the first phase of the questioning referred to public perceptions of wind parks from the perspective of the respondents. Thus, the following elements were questioned: visual elements of wind turbines, such as color, shape, onshore or offshore placement, impact on property value, shadow flickering health damage on citizens issue, the interest and focus of the participants for supporting renewable energy from their energy consumption, as well as their perception towards placing wind turbines offshore or to investing in wind turbines on their own property. The second part of the research regarded strategies wind energy companies should use (in the opinion of the participants) to increase public acceptance and the intention to cover the own need of energy from renewable energy sources.

The research time span was between 1st of June 2015 and $1^{\text {st }}$ of February 2016.

\section{Findings and analysis}

The respondents answered questions regarding the visual, economic and social effects of wind turbines instalments in certain regions, as well as potential methods of increasing public acceptance of wind parks, such as compensation of citizens, promotion methods and involvement of citizens already in the planning phase of such a wind energy projects, as well as strategic partnerships of the wind energy companies with other companies in the field, non-profit organizations, etc.

The first question referred to the visual impact of wind turbines in a certain landscape, due to the color, size, height, distance from residential area, etc. As shown in Figure 1, similar percentages of the Dutch and Romanian respondents classified this aspect as having a high, respectively an average impact on public reaction (in the case of Romania $48 \%$ of the citizens mentioned a high impact, while $42 \%$ of the Dutch respondents mentioned the same). Only $4 \%$ of the Romanian respondents and $17 \%$ of the Dutch respondents mentioned 'No impact' as an answer to this aspect. 


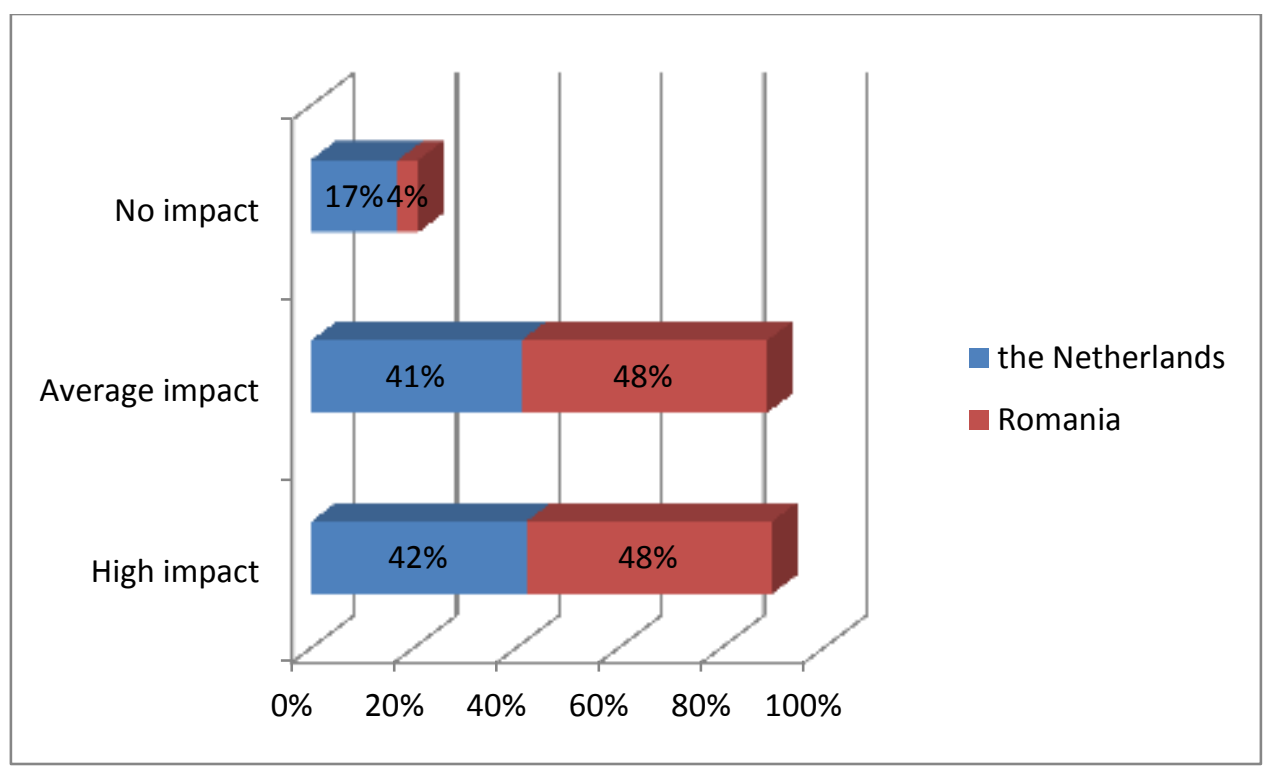

Figure 1. Reactions of Dutch and Romanian citizens on the aspect regarding visual impact of the wind turbines in the landscape

Source: Author's own research.

The respondents who admitted the importance of the visual impact in public reactions mentioned light colors, such as white, grey, they have usually seen already in wind turbines make them acceptable as a presence in a landscape, while the distance from residential areas was also confirmed as an important element for their acceptance. The majority of the Romanian respondents had a positive approach when asked about the instalment and design of wind turbines, considering them as a positive influence in the landscape and modern technology for a sustainable energy, while the Dutch ones were more cautious and reluctant when debating about the subject, involving more objective factors, such as the impact on property value, health, environmental damage and other effects before giving an opinion.

Sixty-five per cent (65\%) of the Romanian respondents described the colors white, grey, blue as having a high impact on the acceptance of the public in the case of wind turbines, $20 \%$ mentioned an average impact and the rest no impact. $34 \%$ of the Dutch participants characterized this aspect of neutral colors as having a high impact, while $65 \%$ mentioned an average impact on the acceptance of the public. Thus, for the Romanian public the

The second aspect inquired already the effect on property value of wind turbines placement, such as the decreasing of property value due to the instalment of wind turbines and their disturbance effects. In this case, the majority of Dutch citizens (55\%) and Romanian citizens (55\%) characterized this issue as an aspect with a high impact on public reaction, namely the potential decrease of property value would increase negative opinion and opposition of the public towards wind parks. Some of the Dutch respondents mentioned in the Netherlands companies already have to order research to prove minimal effects on property value in order to convince the public in the planning phase or even before, their property value will not be affected by the construction of the wind energy project. 


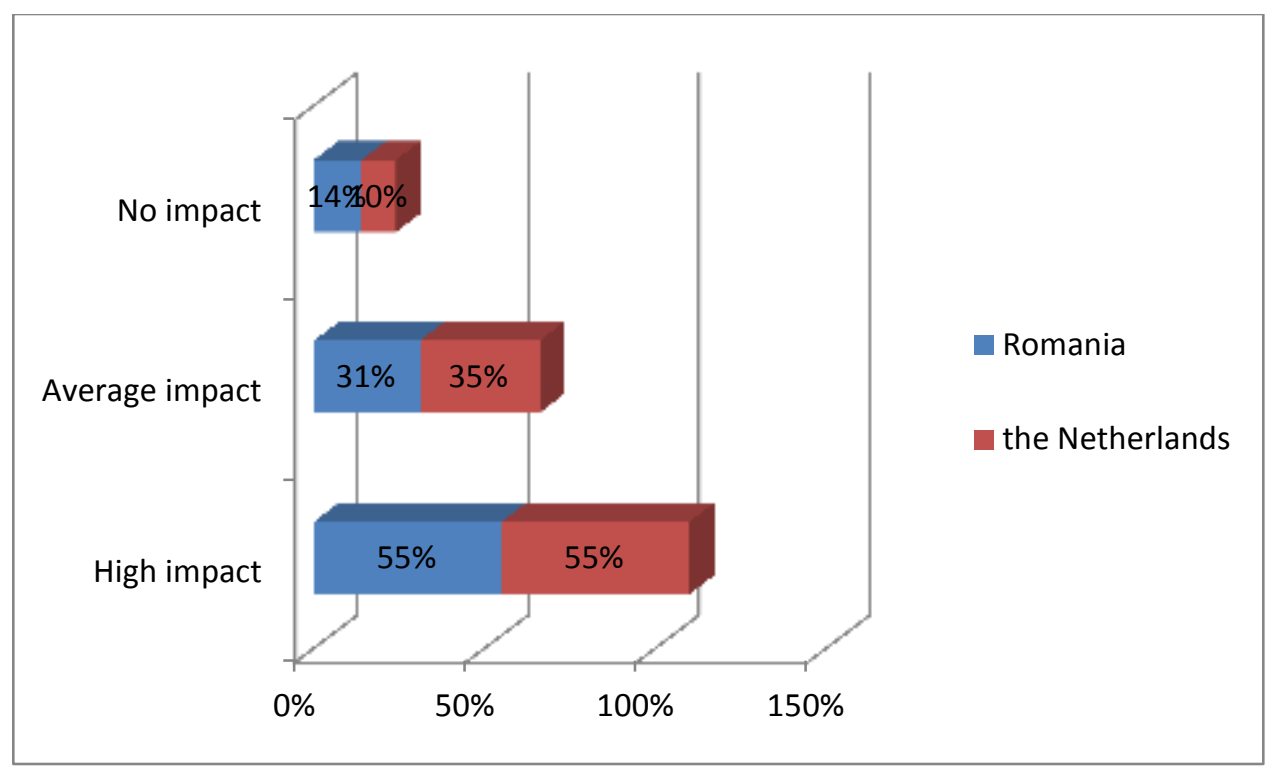

Figure 2. Reactions of Dutch and Romanian citizens on the aspect regarding impact on property value of wind turbines in the sense of potential property value decrease for the citizens living nearby

Source: Author's own research.

Of the Romanian inhabitants mentioning a high impact, 94\% owned their own apartment mentioned a high impact of this aspect on public reaction towards wind turbines at the moment of questioning. $68 \%$ of the Dutch citizens mentioning a high impact of this element on the public reactions of citizens were renting or living with friends/family and the rest 32\% owned their own apartment. Thus, a direct connection between the property feeling and a higher rate of consideration of this aspect could not be established, as also the respondents who rented or lived with friends or family recognized the high importance of property value decrease in increasing opposition and negative reactions of citizens towards placement of wind turbines.

Shadow flickering was considered mostly as an aspect with an average impact by $70 \%$ of the Dutch respondents and by $55 \%$ of the Romanian participants. 35\% of the Romanian participants considered it had no impact on the public reactions of citizens, while $23 \%$ of the Dutch respondents expressed the same.

Another issue that was addressed during the questionings was the health damage that could be caused to the citizens living nearby the wind turbines, such as hearing loss and visual epilepsy. In the case of Dutch citizens the majority 39\% voted as a factor with no impact for public reactions, while $30 \%$ mentioned it was an element with a high impact. In the case of the Romanian citizens 53\% characterized it as a factor with an average influence on public reactions, while 38\% mentioned a high impact. Romanian citizens asked about the potential health issues of wind turbines, as they were not affected so far by them or did not know wind turbines could have negative effects on the health due to the isolation of wind parks in Romania, that are usually built in isolated areas with no or few citizens. On the other hand, the Dutch citizens were more informed about potential health damages because of higher proximity of wind turbines to residential areas, press related to the subject, mouth-to-ear 
propaganda or research in the field. Furthermore, Dutch citizens mentioned objective factors such as possible decrease of property value due to reduced distance to wind turbines, environmental damage or landscape damage, health damage and shadow flickering as essential elements to take into consideration before accepting the instalment of a wind energy park. The Romanian respondents appeared to be much more positive towards new technology instalments for wind energy, usually describing white or grey wind turbines as a positive element, that does not disturb the landscape, while Dutch citizens were more reluctant about new wind turbines placement emphasizing the high degree expansion of wind parks as an element frequently interfering with natural and human habitat.

Another part of the first phase of questioning was to ask the participants if they would agree to support the renewable energy field by paying more for the renewable energy through their own consumption.

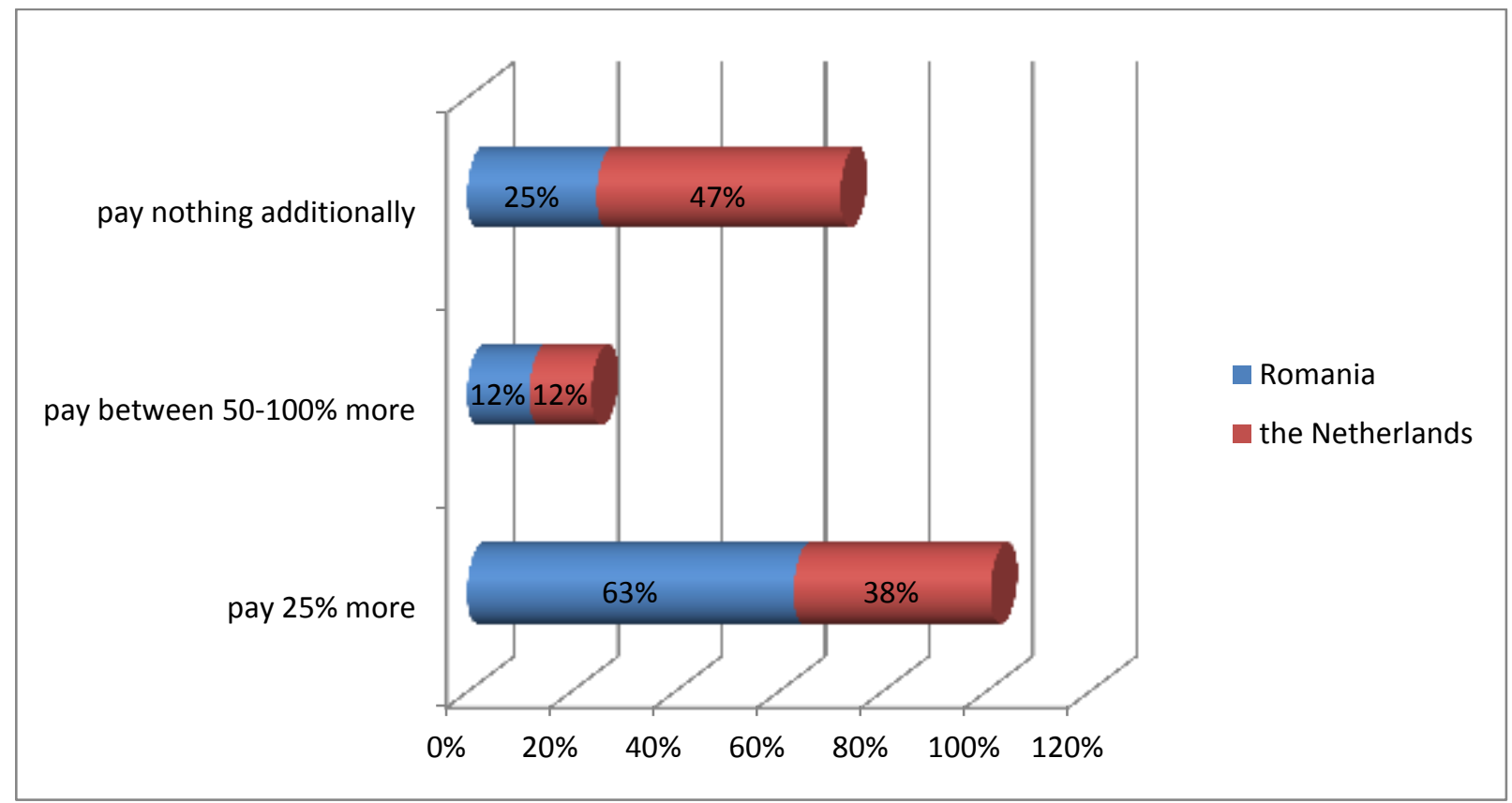

Figure 3. Focus of Dutch and Romanian citizens on the aspect of supporting renewable energy by paying more through their own consumption

Source: Author's own research.

As shown in Figure 3, the majority of the Dutch respondents (47\%) mentioned they would refuse to pay anything additionally for the renewable energy consumption, while $63 \%$ of the Romanian participants agreed to pay $25 \%$ additionally for the renewable energy. Only 38\% of the Dutch citizens that participated in our inquiry would accept to pay $25 \%$ more for renewable energy.

The following aspect debated in the questioning was the public perception of the respondents regarding possible placements of wind turbines, whether onshore on the property of the respondents, onshore close to an archaeological site or offshore. Referring to the issue of placing wind parks or wind turbines close to archaeological sites, a majority of $48 \%$ of the respondents from the Netherlands mentioned they "would not mind". Only 38\% of the Dutch participants would oppose it. On the contrary, $50 \%$ of the Romanian participants expressed opposition to such a 
placement, as damaging the landscape of the archaeological site, while 35\% would not mind and the rest could not offer an answer as they did not know yet.

Offshore wind turbines appeared to be much more accepted by both Dutch participants (69\%) and Romanian respondents (58\%), who declared they would strongly support it, as not interfering directly with the natural and human habitat. $12 \%$ of the Dutch citizens were still cautious when answering and mentioned they would give an answer depending on the impact of the offshore wind turbines on the environment or on other circumstances related to the wind energy project, while $4 \%$ of the Romanian citizens mentioned specifically they would support such a construction as long as it would not affect sea life, transport, landscape, tourism, etc. Although in the last years, the Netherlands was confronted with significant protests, the Dutch respondents from our inquiry were still more in favor of offshore wind parks than onshore ones, because the first ones still do not interfere as much with residential areas or the environment as the onshore ones do.

The investment in wind turbines on their own property in order to produce renewable energy represented the next topic to be debated, where $45 \%$ of the Dutch respondents would agree to invest in such a project, while only $20 \%$ of the Romanian respondents mentioned they would be interested for the next years. A significant amount of $34 \%$ of the Dutch participants and $20 \%$ of the Romanian participants mentioned they would not be interested. The remaining Dutch participants mentioned they did not know yet, were not property owners, so could not invest in such a project or would only be interested in wind turbines on their property if they would get subventions for the project. The financial aspect was emphasized as a significant element for being interested for such an investment by the respondents from the Netherlands, while $60 \%$ of the Romanian respondents mentioned they did not know what to answer. Dutch respondents were more aware of the existence of subventions from the government or companies' incentives for citizens in order to accept the placement of wind turbines close to or on the citizens property in comparison with the Romanian respondents. This could be explained due to the differences in wind energy expansion in the two countries, which although comparable, has larger effect in the Netherlands due to the restrained available surface and being felt by the citizens in comparison to Romania, where there is a broad available surface and wind energy projects are built in areas far from residential regions in general.

Potential strategies of attracting positive public reactions and support, that companies could use was the last point of interest questioned in our study. In this part the motivation through the financial compensations offered by such companies were investigated and received an important emphasis by the majority of the respondents in the study. As one can observe in Table 3, 50\% of the Dutch and $68 \%$ of the Romanian participants mentioned shares or an yearly amount as being motivating and an efficient method for gaining more public acceptance. The Dutch respondents mentioned these methods are already implemented in the Netherlands by wind energy companies that install their project close to or in residential areas. This is one of the main strategies to avoid legal problems with the inhabitants and also avoid image damage and additional costs, fines through protests against such a placement. The majority of the respondents selected numerous methods of increasing public 
acceptance and not only one, motivating more incentives would be efficient on different social, psychological, economic and political contexts.

Important methods of motivating public acceptance of wind projects are:

- research in the field to demonstrate no or scarce effects of wind farms on environment and property value, affirmed by 38\% of the Romanian respondents and $17 \%$ of the Dutch respondents, as shown in Table 1. The Dutch participants mentioned this is an important method of demonstrating the minimal risks, to which citizens are exposed if a wind energy project is constructed in a certain environment. The landscape damage, damage of flora and fauna, as well as the possibility of property value decrease, an objective factor of decision, are significant elements for gaining supporters or opponents of the own projects. The Romanian citizens participating in the study mentioned however the financial compensation factor as with a higher impact for increasing public acceptance of wind turbines instalment than research demonstration since the planning phase of the wind turbines placement ( $30 \%$ of the Romanian respondents and $47 \%$ of the Dutch respondents).

-educating citizens about the necessity of using other forms of energy, namely renewable energy, was another method mentioned by $5 \%$ of the Romanian participants.

Table 1. Selected strategies of wind energy companies for the purpose of increasing public acceptance (according to the answers of Dutch respondents)

\begin{tabular}{|c|c|}
\hline $\begin{array}{c}\text { Percentage of respondents, who stated the } \\
\text { method }\end{array}$ & $\begin{array}{c}\text { Methods of increasing acceptance of wind } \\
\text { turbines }\end{array}$ \\
\hline $50 \%$ & Yearly amount to citizens close to wind parks. \\
\hline $47 \%$ & Shares within wind energy company to citizens. \\
\hline $47 \%$ & $\begin{array}{c}\text { Co-operating with inhabitants for decision taking } \\
\text { in the planning of the wind energy project } \\
\text { (placement of wind turbines, etc.). }\end{array}$ \\
\hline $17 \%$ & $\begin{array}{c}\text { Research to prove no/ scarce effects of wind } \\
\text { turbines on environment, visual landscape and } \\
\text { property value. }\end{array}$ \\
\hline $19 \%$ & $\begin{array}{c}\text { Endorsement of wind energy project through } \\
\text { strategic partnerships (with government, other } \\
\text { wind energy companies, etc.). }\end{array}$ \\
\hline
\end{tabular}

Source: Authors' own research.

\section{Conclusion}

As a conclusion the first hypothesis was partly confirmed, as $64 \%$ of the Romanian respondents agreed the light colors of wind turbines would have a high impact on public reactions, while only 34\% of the Dutch citizens expressed the same opinion. Another unexpected conclusion was that the second hypothesis was not confirmed, as the majority of the Dutch respondents (47\%) mentioned they would not agree to pay anything additionally for the renewable energy consumption, while $63 \%$ of the Romanian participants agreed to pay $25 \%$ additionally for the renewable energy. Although the hypothesis was taken considering the financial potential of both countries and their citizens, the mentality of Romanian respondents that was predominantly for the expansion of wind turbines, seemed to influence their decision in making an extra financial effort to support this sector. On the contrary, the majority 
of the Dutch participants were not willing to pay anything additionally even if the benefits of wind energy were taken into consideration.

The debate on public reactions being motivated by several factors, such as mentality, design, financial compensations, etc, has become a main issue of research in the scientific literature, but also in the business field, as wind energy companies become more exposed to such reactions. Although, the financial factor may seem the main one for motivating citizens either to accept the presence of wind turbines in their residential area or to support the renewable energy sector through paying additionally for their own consumption, these aspects are not always confirmed, as factors such as the openness towards sustainable technology additions, involvement or distance from renewable energy projects counterbalance this affirmation. The necessity of the cooperation and direct involvement of more stakeholders, that will be co-inhabitants of the wind turbines regions, has become obvious from early stages, respectively in the planning stage. The local governments' contribution to decision making of the placement of wind turbines projects should also not be neglected, as these institutions are a key stakeholder with potential direct influence on the renewable energy project's future.

Thus, increasing public acceptance of wind farms will be influenced by numerous factors already mentioned, but also depending on the education of consumers and citizens in understanding the need of compromise and the opportunities brought by the instalment of renewable energy projects, that will be able to ensure a green energy for the coming years.

As an objective for future research, is the observation of wind energy companies' strategies evolution in the direction of consumers' acceptance, but also the political and government efforts in balancing the need of expansion for renewable energy producers and ensuring the sufficiently natural landscape for inhabitants. These elements are worth analyzing also on the level of the European Union, but also locally on a national level, depending on the social, economic and political factors of each country.

\section{Disclaimer}

A shorter version of this article was presented during the 10th International Conference on Business Excellence in Energy, Climate Change and Sustainability (ICBE) in Bucharest, Romania, on the 3rd of March 2016, and published in the conference proceedings.

\section{References}

Abe, K., Saito, T., Taguchi, M., Mishima, N. (2016), "A Study on Reaction of Residents to Wind Turbines to Promote Local Economy", Procedia CIRP, Vol. 40, pp. 463468.

Berndt, M. L. (2015), "Influence of concrete mix design on CO2 emissions for large wind turbine foundations", Renewable Energy, Vol. 83, pp. 608-614.

Blyth, D. (2015), "Protests against giant wind turbines in Dutch-Flemish border area", Flanderstoday, available at: http://www.flanderstoday.eu/politics/protestsagainst-giant-wind-turbines-dutch-flemish-border-area (accessed September 4th, 2016).

Vol. 11, No. 3, Autumn, pp. 532--543, ISSN 1842-0206 | Management \& Marketing. Challenges for the Knowledge Society 
David Suzuki Foundation. (2013), "Wind power opponents may be blowing hot air", available at: http://www.davidsuzuki.org/blogs/sciencematters/2013/04/wind-power-opponents-may-be-blowing-hot-air/(accessed September 4th, 2016).

de Boer, J., Zuidema, C. (2013), "Towards an integrated energy landscape”, Paper for AESOP-ACSP Joint Congress, available at: http://www.edgarprogram.com/uploads/fckconnector/e887aba0-681d-4e00-ae4 (accessed September 5th, 2016).

DutchNews. (2014), "Tourist companies join protests about offshore wind farms", DutchNews.nl, available at: http://www.dutchnews.nl/news/archives/2014/02/tourist_companies_add_t o_prote/ (accessed September 6th, 2016).

Eggink, E. (2013), "Offshore Wind Power Together Towards Social Support - An analysis of three key-stakeholder groups in the Netherlands and their views on social acceptance issues", Utrecht University,

Groothuis, P.A., Groothuis, J.D., Whitehead, J.C. (2008). "Green vs. green: measuring the compensation required to site electrical generation windmills in a viewshed", Energy Policy, Vol. 36, pp. 1545-1550.

EWEA. (2015), "Wind in power. 2014 European statistics", EWEA, available at: http://www.ewea.org/statistics/ (accessed September 10th, 2016).

EWEA (2016), "Public acceptance of wind energy", EWEA, available at: http://www.ewea.org/policy-issues/public-acceptance/ (accessed September 10th, 2016).

Jay, S.A. (2008), At the Margins of Planning: Offshore Wind Farms in the United Kingdom, Ashgate: Aldershot.

Lilley, M.B., Firestone, J., Kempton, W. (2010), “The Effect of Wind Power Installations on Coastal Tourism", Energies, Vol. 3, pp. 1-22.

Navrud, S., Bråten, K.G. (2007), "Consumers' Preferences for Green and Brown Electricity: a Choice Modelling Approach", Revue d'économie politique, Vol. 117, pp. 795-811.

Wolsink M. (2007), "Planning of renewables schemes: Deliberative and fair decisionmaking on landscape issues instead of reproachful accusations of noncooperation", Energy Policy, Vol. 35, No. 5, pp. 2692-2704,

Wolsink M. (2010), "Near-shore wind power-protected seascapes, environment talist's attitudes and the technocratic planning perspective", Land Use Policy, Vol. 27, pp. 195-203. 